\title{
Miecz późnośredniowieczny z Wolina
}

Late Medieval Sword from Wolin

\begin{abstract}
Abstrakt: Artykuł prezentuje znalezisko żelaznego miecza dokonane w Wolinie (woj. zachodniopomorskie) podczas budowy basenu jachtowego w 2013 r. Zabytek zachował się fragmentarycznie w postaci rękojeści z ułamkiem głowni. Ogólny kształt i proporcje pozwalają umieścić go w typie XIIIa w klasyfikacji E. Oakeshotta, a jelec i głowice odpowiednio w stylu 2 i typie J typologii tego badacza. Na dolnej partii
\end{abstract}

zachowanego fragmentu głowni widoczne są bliżej niezidentyfikowane znaki wykonane żółtym metalem. Miecze typu xıIIa reprezentują jedną z najpowszechniejszych form oręża - w Polsce zarejestrowano dotychczas co najmniej $36 \mathrm{eg}$ zemplarzy, z czego i na terenie Pomorza Zachodniego. Biorąc pod uwagę wszystkie informacje, opisany miecz datować można na drugą połowę XIII i XIV w. (być może jego pierwszą połowę?).

Słowa kluczowe: Pomorze Zachodnie, Wolin, późne średniowiecze, Głosek, Oakeshott, miecze

W latach 20II-20I3 Instytut Archeologii i Etnologii PAN w Szczecinie prowadził nadzór i badania archeologiczne podczas budowy portu żeglarskiego w Wolinie. Inwestycja ta zlokalizowana była bezpośrednio na południe od Starego Miasta, pomiędzy nim a tzw. Południowym Przedmieściem. Obszar ten zewidencjonowany jest jako stan. 3 (AZP 2I-06/34). Powstający na zachodnim brzegu Dziwny basen jachtowy stał się miejscem spektakularnych odkryć. Szczególnie interesujące są zwłaszcza relikty nabrzeży z wczesnego średniowiecza oraz czasów późniejszych (por. Janowski 20I3; 2014). W ich obrębie natrafiono na szereg różnorodnych przedmiotów, a jednym z nich jest tytułowy oręż znaleziony w $2013 \mathrm{r}$. w nawarstwieniach budujących nowożytne nabrzeże ${ }^{1}$.

Miecz przetrwał do dziś fragmentarycznie w postaci rękojeści z głowicą i jelcem oraz ułamkiem głowni (ryc. I). Całkowita długość tego fragmentu wynosi 4 or mm, a waga 1138 g. Najlepiej zachowaną częścią jest masywna rękojesśc, której trzpień ma długość $264 \mathrm{~mm}$, a na chwyt przypada $198 \mathrm{~mm}$. Trzpień jest zgięty i lekko pęknięty w połowie długości. Przekrój trzpienia jest czworoboczny i wyraźnie rozszerza się on w kierunku jelca. Pod głowicą jego wymiary wynoszą $16,3 \times 5,2 \mathrm{~mm}$,

1 Zabytek zainwentaryzowano pod numerem pol. w3/2012/0/791. 


$$
\text { It }
$$




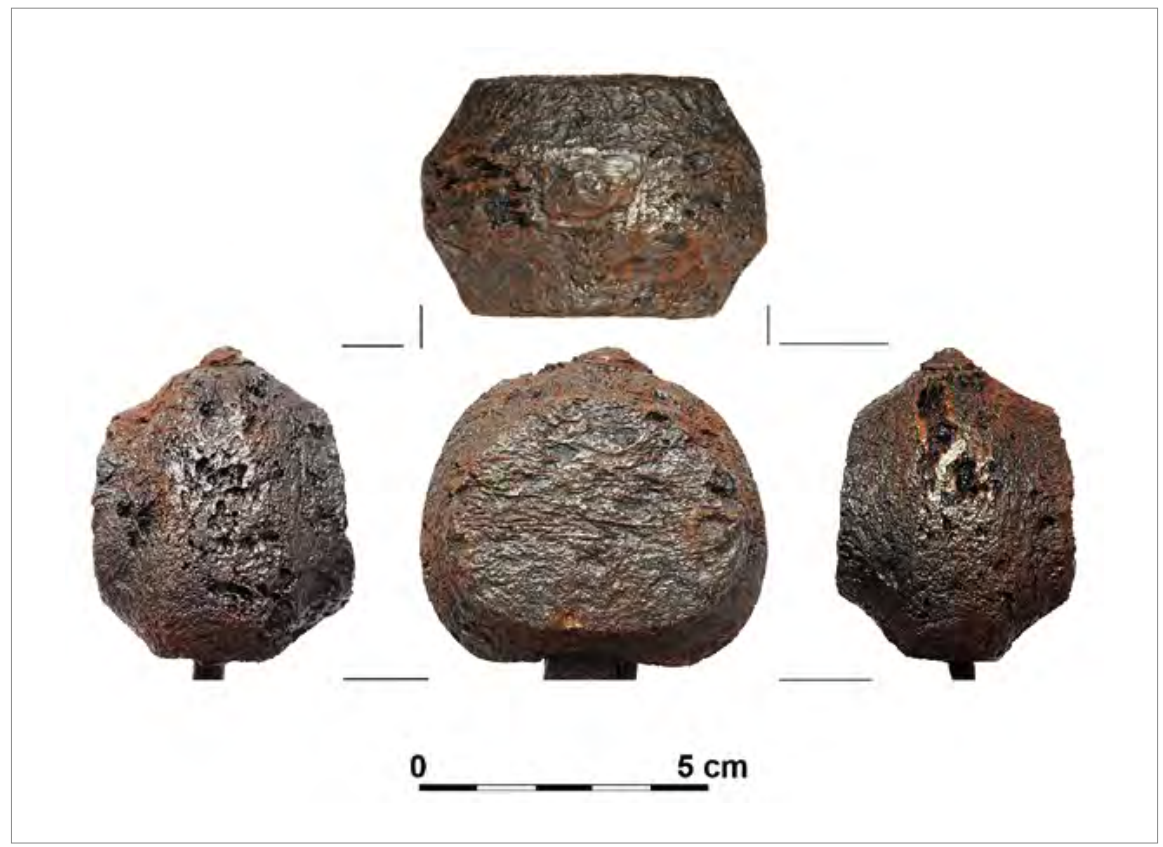

Ryc.2. Wolin, gm. loco, stan.3. Głowica miecza odkrytego w 2013 r. (fot. A. Janowski).

a przy jelcu 31,6 $\times 6,4 \mathrm{~mm}$. Trzpień wystaje około $5 \mathrm{~mm}$ ponad głowicę i zaklepany został na czworobocznej żelaznej podkładce. Być może pierwotnie miała ona formę niewielkiej piramidki, obecnie zdeformowanej przed korozję. Głowica en face ma kształt owalny, natomiast w rzucie bocznym i z góry jest oktagonalna. Jej szerokość wynosi 60 mm, wysokość 52, I mm, a grubość 42,2 mm (ryc. 2). Jelec jest prosty i stosunkowo długi ( $180 \mathrm{~mm})$. Ramiona mają czworoboczny przekrój przy trzpieniu i są wyraźnie szersze na końcach, a ich przekrój zmienia się na ośmioboczny (wymiary odpowiednio I8,4 × 16,1 i 17,4 × I4,89 mm). Z głowni zachował się jedynie fragment o długości $137 \mathrm{~mm}$. Jej grubość pod jelcem wynosi 5,6 mm, a w miejscu złamania 4,4 mm. Na zachowanym ułamku widać, że głownia lekko zwęża się ku sztychowi - szerokości pod jelcem wynosi 57,5 mm, a w miejscu złamania 49,3 mm. Zbrocze jest bardzo płytkie i dość szerokie - I8,5 mm. Na obu płazach, odpowiednio 90 i $92 \mathrm{~mm}$, poniżej jelca widoczne są znaki wykonane żółtym metalem (stop miedzi?) techniką inkrustacji. Mają one wysokość I5 mm. W pierwszym przypadku $23 \mathrm{~mm}$ poniżej pierwszego znaku widoczny jest fragment kolejnego (ryc. 3). W drugim przypadku $13 \mathrm{~mm}$ poniżej pierwszego znaku widoczny jest natomiast $\mathrm{x}$ wykonany srebrzystym metalem (ryc. 4). Słaby stan zachowania nie pozwala, niestety, na identyfikację znaków. Nie uczytelniły ich również zdjęcia RTG (ryc. 5). 


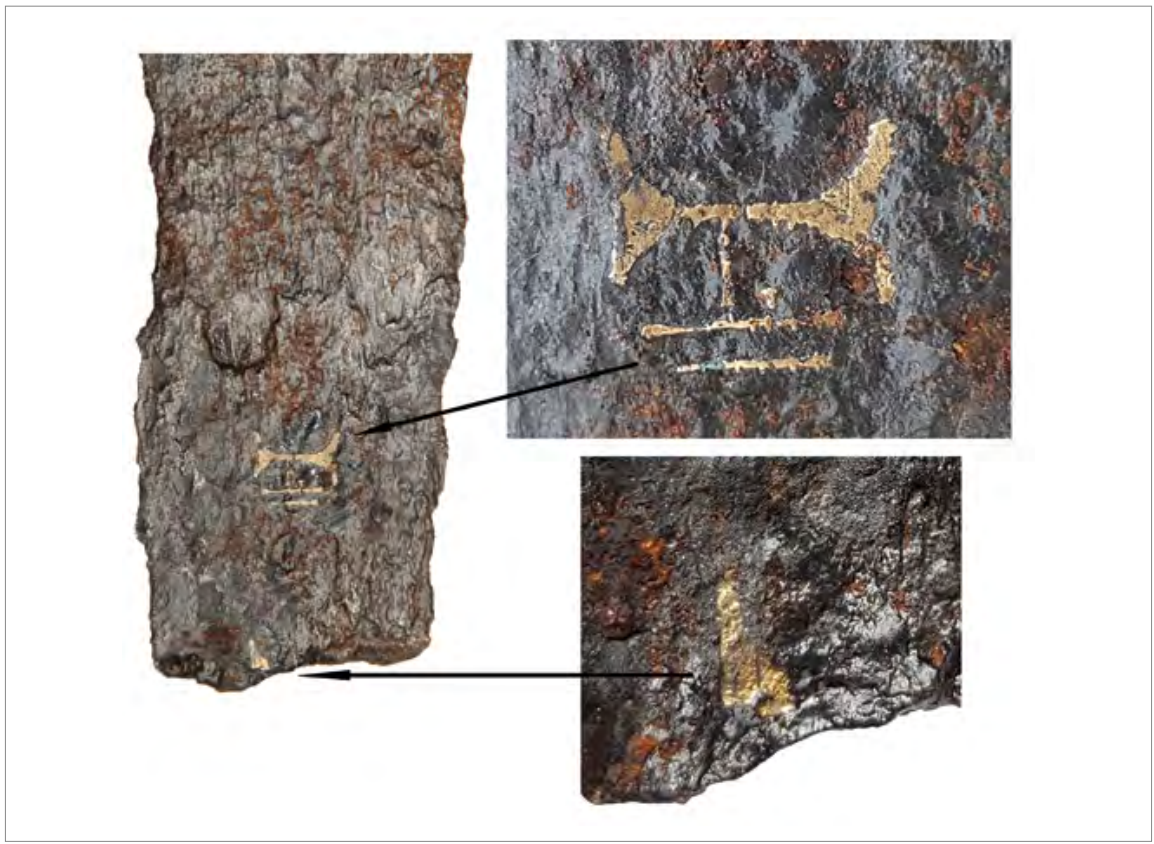

Ryc. 3. Wolin, gm. loco, stan. 3. Znaki na głowni miecza odkrytego w $2013 \mathrm{r}$. (fot. A. Janowski).

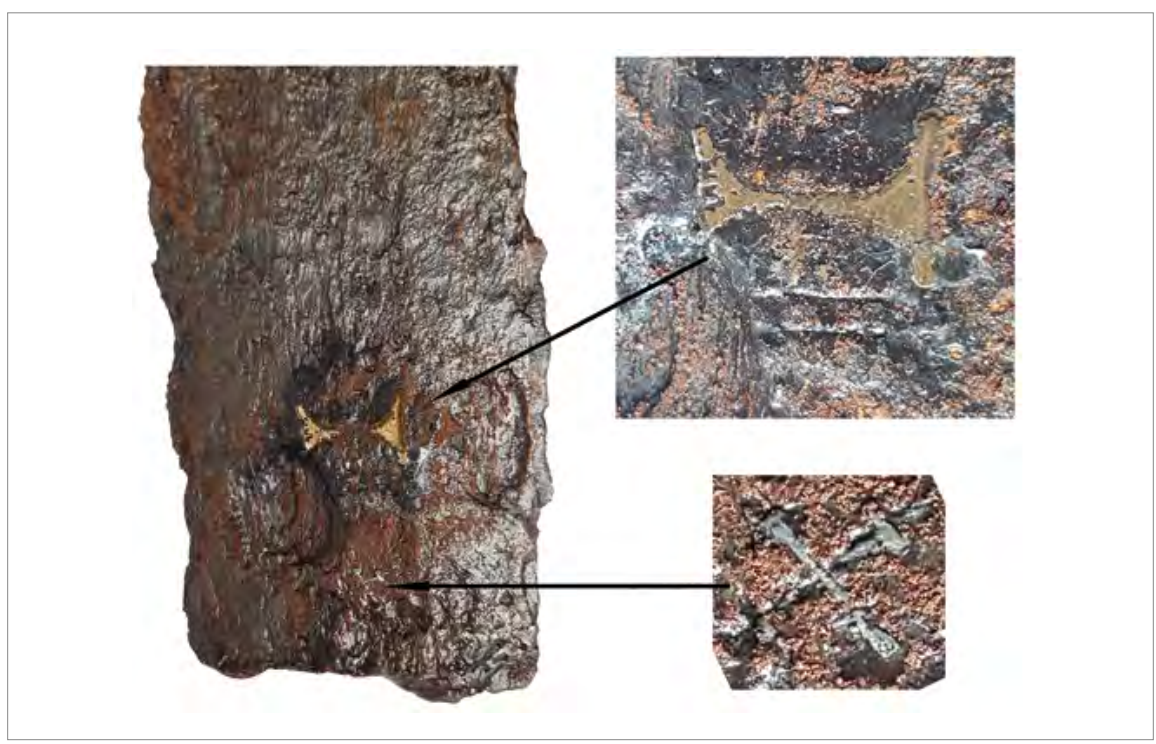

Ryc.4. Wolin, gm. loco, stan. 3. Znaki na głowni miecza odkrytego w 2013 r. (fot. A. Janowski). 
Biorąc pod uwagę ogólny kształt i wymiary, miecz z Wolina bez większych wątpliwości przyporządkować można do typu XıIIa w klasyfikacji Ewarta Oakeshotta (1998: 42-47; por. Głosek 1984: 28, ryc. 2; Aleksić 2007: 84). Bez trudności umiejscowić typologicznie można także jelec, który reprezentuje styl $2 \mathrm{w}$ systematyce tego badacza (Oakeshott 1998: II4; por. Głosek 1984: ryc. 4). Bardziej problematyczne jest natomiast przyporządkowanie głowicy, w swojej klasyfikacji E. Oakeshott (1998: 95-96) wyróżnił bowiem kilka typów - H, I, J, K - których kształt en face przypomina owal lub koło, a w rzucie bocznym i z góry jest oktagonalny. Różnice pomiędzy nimi dotyczą m.in. sposobu wyodrębnienia ścianek tarczek bocznych. Głowica miecza z Wolina plasuje się pomiędzy klasycznym typem I a J. Biorąc pod uwagę lekko wklęsły kształt ścianek tarczek bocznych, skłonny jestem jednak uznać ją raczej za okaz typu J (Oakeshotta 1998: 96; por. Aleksić 2007: 49-53, Fig. I).

W monografii z I984 r. Marian Głosek (1984: 28, 30, I8I) podał informacje o 7I mieczach typu XIIIa na terenie Europy Środkowej, w tym 30 w zbiorach polskich. W momencie jej powstawania był to drugi najliczniejszy typ miecza późnośredniowiecznego, ustępujący liczebnością jedynie typowi xvia, który stanowił kolejny etap ewolucji tego rodzaju broni. Późniejsze znaleziska jedynie potwierdziły uniwersalność i popularność tego oręża. Wśród nowych odkryć z Polski wspomnieć należy o okazach ze Strzegocic i Tarnowa w Małopolsce (Szope 1985), Dynowa na Rzeszowszczyźnie (Glinianowicz, Kotowicz 2009: 190-194), czy Gniewu na Pomorzu Gdańskim (Żabiński 2017) i Raczek na Żuławach (Marek 20I4: 55-58, I54, nr kat. I27). Z terenu Czech i Słowacji znanych było w $1984 \mathrm{r}$. dziesięć mieczy typu XıIIa, a dziś z samych tylko Czech z większym lub mniejszym prawdopodobieństwem zaklasyfikować można do niego aż 5 I okazów (Hošek i in. 2019: nr kat. 6, II, 33-34, 38, 40, 49, 5I-52, 54-57, 65, 68, 78, 92, 99, III, II6, I57, 166, 179, 190, 204, 209, 218-219, 229, 251, 265, 272-273, 283, 284, 286, 288-289, 300, 308, 311-312, 319, 327, 344, 348, 352-353, 363, 368, 380), czyli blisko I2\% wszystkich średniowiecznych mieczy z tego obszaru. Z kolei w Europie południowo-wschodniej liczba znalezisk zbliża się do 70 (por. m.in. Aleksić 2007: 84; Bencze, Gáll 2011; Culic, Pralea 2013; Sijarić 2014: 90-91, 102-103).

Na terenie zachodniej części Pomorza i pogranicza pomorsko-lubuskiego oprócz omawianego znaleziono jak dotychczas jeszcze dziesięć egzemplarzy mieczy typu XIIIa (por. Głosek 1984: nr kat. II5, 231, 246, 309, 319, 341, 379-382) (ryc. 6). Bez wyjątku są to znaleziska przypadkowe, niekiedy o niepewnym pochodzeniu. Dwa z nich wyłowiono z rzek - okazy z Santoka i Szczecina (Głosek 1984: nr kat. 309, 319), a jeden odkryto na grodzisku (Barnówko - Głosek 1984: nr kat II5). W pięciu przypadkach nie znamy miejsca znalezienia (Głosek 1984: nr kat. 34I, 379-382).

Pod względem kształtów, a tym samym przynależności typologicznej elementów rękojeści, jest to zbiór dość homogeniczny. Wszystkie głowice są zbliżone 


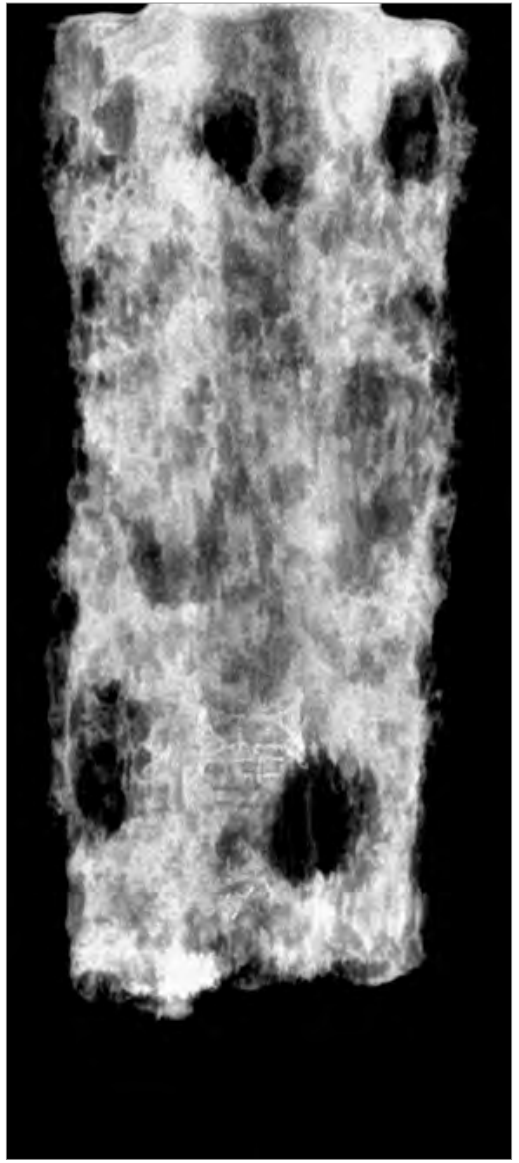

Ryc.5. Wolin, gm. loco, stan.3.

Zdjęcie RTG głowni miecza odkrytego w $2013 \mathrm{r}$.

en face do owalu: typ H2 (Szczecin - Głosek 1984: nr kat. 319), I (Santok, zbiory MNS - Głosek 1984: nr kat. 309, 38I), J (Gorzów Wlkp., zbiory MNs - Głosek I984: nr kat. 246, 382 ) lub K (Barnówko, Cerkwica, zbiory MNS - Głosek I984: nr kat. II5, 23I, 380). Jelce zachowały się tylko w sześciu mieczach i należą do stylów I (Barnówko - Głosek 1984: nr kat. I15), ib (Szczecin - Głosek 1984: nr kat. 319) i 2 (Gorzów Wlkp., zbiory MNs (2 egz.) - Głosek 1984: nr kat. 246, 380, 382). Wyjątek stanowi jeden z okazów szczecińskich w stylu 7 (Głosek 1984: nr kat. 38I). Kombinacje tych składowych były różne, ale w dwóch przypadkach (Gorzów Wlkp. i okaz ze zbiorów MNS) była ona identyczna jak w mieczu wolińskim (por. Głosek I984: nr kat. 236, 382). Taka konfiguracja - XIIIa, J, 2 - pomimo powszechności występowania poszczególnych elementów składowych, jest stosunkowo rzadka. Wśród 7 I okazów analizowanych przez M. Głoska wystąpiła ona jedynie w tych dwóch egzemplarzach. Dziś ten korpus jest nieco liczniejszy. Z Polski do wspomnianych doliczyć należy miecz wyłowiony z Tyny w miejscowości Raczki koło Elbląga (Marek 20I4: 55-58, 154, nr kat. I27, ryc. 21) oraz z Wisły w okolicy Gniewu (Żabiński 20I7)2. Wśród materiałów z Europy południowo-wschodniej Marko Aleksić (2007: nr kat. 356) wyróżnił tylko jeden miecz z taką kombinacją, na 62 znane mu okazy typu XıIIa ${ }^{3}$. O zaledwie trzech egzemplarzach w kolekcjach zachodnio-

2 Problemy stwarza jednoznaczne zaklasyfikowanie miecza ze Starego Sącza. Według Mariana Głoska (I984: nr kat. 316) jest to kombinacja XIIIa, H, 2, z kolei M. Cabalska i W. Mazur (I982:9) klasyfikują go jako XIIIa, J, 2, a ostatnio pojawiła się próba pogodzenia tego stanowiska - XIIIa, H/J, 2 (Żabiński i in. 2015: Appendix 3, nr kat. 190).

3 Egzemplarzy takich może być więcej, istnieją bowiem rozbieżności w ustaleniach typologicznych pomiędzy badaczami. Przykładowo Mirsad Sijarić (2014: 92, 98 ) jeszcze co 


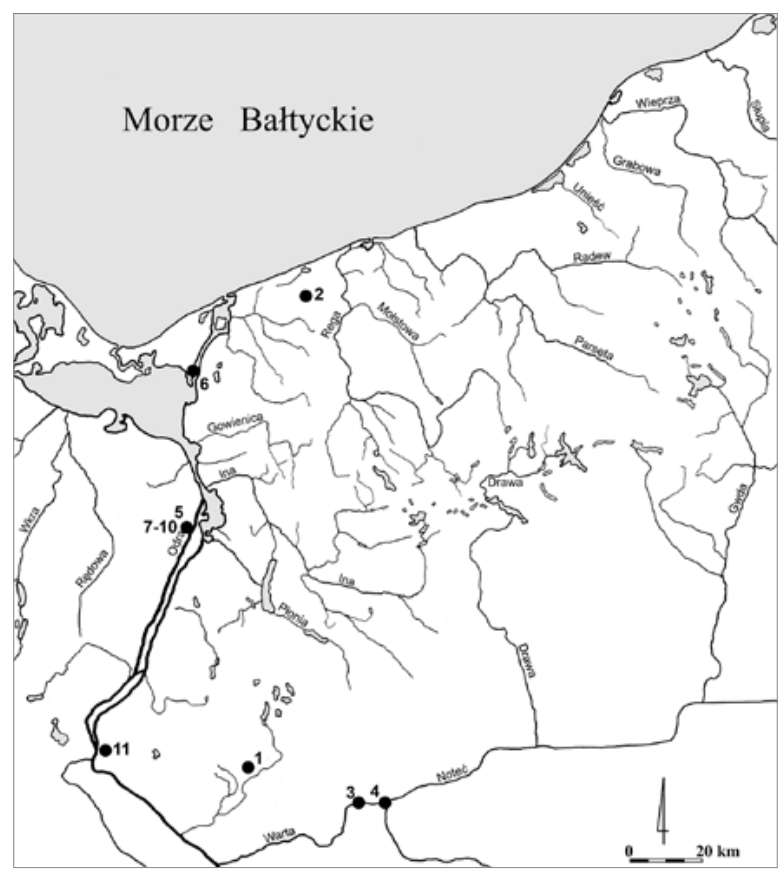

\section{Ryc. 6.}

Rozmieszczenie

znalezisk mieczy typu

XIIIa wg E. Oakeshotta

na Pomorzu i pograniczu

pomorsko-lubuskim:

I - Barnówko;

2-Cerkwica;

3- Gorzów Wlkp.;

4-Santok;

5-Szczecin;

6 - Wolin;

7-IO - miejsce znale-

zienia nieznane (zbiory

Muzeum Narodowego

w Szczecinie);

II - miejsce znalezienia

nieznane (zbiory

Muzeum w Cedyni)

(opr. A. Janowski).

europejskich wspomina Ewart Oakeshott (2000: 98-99, 105). Zdecydowanie najliczniejszy zbiór pochodzi z Czech, gdzie zidentyfikowano osiem mieczy typu XIIIa, J, 2 (Hošek i in. 2019: nr kat. 34, 56, 65, 92, III, 265, 300, 327).

Miecze typu XIIIa były formą długotrwałą. Najstarsze okazy pojawiły się już na początku XIII w., ale ich znaleziska znamy również z kontekstów datowanych na XV-XVI w. Największą popularnością broń ta cieszyła się jednak w drugiej połowie XIII i w XIV stuleciu (Oakeshott 1998: 42; 2000: 2, I2, I00-IO8; Aleksić 2007: 84). Również jelce w stylu 2 są formą występującą w długim odcinku czasu (Aleksić 2007: 95). Nieznacznie większa precyzja ustaleń chronologicznych możliwa jest jedynie w odniesieniu do głowic typu J, które stały się charakterystycznym elementem miecza około połowy XIII i pozostawały nim do początku XV w. (Oakeshott 1998: 96). Miecz z Wolina znaleziony został na złożu wtórnym w nawarstwieniach nowożytnych, ale warto przyjrzeć się chronologii egzemplarzy o analogicznej kompozycji. Przykłady mieczy typu XIIIa, J, 2 przytoczone przez Ewarta Oakeshotta (2000: 98-99, IO2) datowane są dość wcześnie, bo na drugą połowę XIII - pierwszą połowę XIV w. Analogicznie

najmniej dwa miecze klasyfikuje jako XııIa, J, 2, mimo iż Marko Aleksić (2007) ma odmienne zdanie. Bez dostępu do zabytków rozstrzygnięcie tej kwestii nie jest możliwe. 
ustalono chronologię okazów polskich (Głosek 1984: nr kat. 246, 382; Michalak 20I3: I40-I4I; Żabiński 2017: 166-167). Z kolei Marko Aleksić (2007: nr kat. 356) jedyny wyróżniony przykład datuje bardzo precyzyjnie na połowę XIV w. Najmłodsze są miecze czeskie. Chronologię pięciu z nich ustalono na XIV w. (Hošek i in. 2019: nr kat. 34, 56, 92, III, 327), a trzech dalszych na XIV - początek lub pierwszą połowę XV w. (Hošek i in. 2019: nr kat. 65, 265, 300). Biorąc pod uwagę powyższe, uprawnione jest datowanie wolińskiego miecza na drugą połowę XIII - XIV w. (pierwszą połowę ?). Pojawienie się tego oręża na polu walki było uzasadnione rozwojem osłon ciała, który nastąpił w połowie XIII w. Dotychczasowa broń stała się niewystarczająca, by przełamać obronę przeciwnika, a jednym z rozwiązań było zwiększenie rozmiarów i wagi miecza w celu zadawania jak najcięższych ciosów. Efektem ewolucji były m.in. okazy takie jak miecze typu XIIIa, których długość dochodziła do $130 \mathrm{~cm}$, a waga do $2 \mathrm{~kg}$. Była do broń ciężka i powolna, a przy tym poruszana siłą obu rąk, co wykluczało użycie tarczy do zasłaniania się i parowania ciosów. Fakt ten nie pozostał bez wpływu na sposób prowadzenia walki i prowadził do dalszego zwiększania rozmiarów i masy, co w efekcie doprowadziło do pojawienia się pod koniec XIV w. tzw. długich mieczy.

\section{Bibliografia}

Aleksić M. (2007), Mediaeval Swords from Southeastern Europe. Material from $12^{\text {th }}$ to $15^{\text {th }}$ Century, Selbstverl., Belgrade.

Bencze U., Gáll E. (20II), A Fourteenth Century Sword from Moldoveneşti

(Hung.: Várfalva), „Studia Universitatis Cibiniensis, Seria Historica”, 8, Supplementum, I, s. 133-138.

Cabalska M., Mazur W.(1982), Średniowieczne militaria z Polski Potudniowej w świetle badań metaloznawczych, „Studia do Dziejów Dawnego Uzbrojenia i Ubioru Wojskowego", 8, s. 7-17.

Culic D., Pralea A. (2013), A Medieval Sword Discovered in Maramures, „Acta Musei Porolissensis", 35, s.303-310.

Glinianowicz M., Kotowicz P.N.(2009), Dwa nieznane późnośredniowieczne miecze z potudniowo-wschodniej Polski, [w:] P. Kucypera, P. Pudło, G.Żabiński (red.), Arma et Medium Aevum. Studia nad uzbrojeniem średniowiecznym, Wydawnictwo Adam Marszałek, Toruń, s. 182-197.

Głosek M. (1984), Miecze środkowoeuropejskie $z X-X V w$., Wydawnictwa Geologiczne, Warszawa.

Hošek J., Košta J., Žákovský P. (2019), Ninth to Mid-sixteenth Century Swords from the Czech Republic in their European Context, part I, The Finds, The Czech Academy of Sciences, Brno. 
Janowski A. (2013), Harbours of Early Medieval Wolin in the Light of Recent Research, [w:] M. Bogucki, M. Rębkowski (red.), Economies, Monetisation and Society in the West Slavic Lands 800-I200 AD, Wydawnictwo IAE PAN; Wydawnictwo WH US Szczecin (Wolińskie Spotkania Mediewistyczne, 2), s. 45-58.

Janowski A.(2014), W wolińskim porcie... / In Wolin’s Port..., Muzeum Regionalne im. Andrzeja Kaubego, Wolin.

Marek L.(2014), Europejski styl. Militaria z Elblaga i okolic, Wydawnictwo Uniwersytetu Wrocławskiego, Wrocław.

Michalak M. (2013), Swords and Falchions from the Polish-Silesian-Brandenburg Borderland ( $2^{\text {nd }}$ half of the $3^{\text {th }}-I^{\text {st }}$ half of the $I 6^{\text {th }}$ cent.). Preliminary Thoughts, [w:] L. Marek (red.), Weapons Bring Peace? Warfare in Medieval and Early Modern Europe, University of Wrocław. Institute of Archeology, Wrocław (Wratislavia Antiqua, 18), s. 137-156.

Oakeshott E. (1998), The Sword in the Age of Chivalry, wyd. 2, Boydell Press, London.

Oakeshott E. (2000), Records of the Medieval Sword, Boydell Press, Woodbridge.

Sijarić M. (20I4), Hladno oružje iz Bosne i Hercegovine u arheologiji razvijenog i kasnog srednjeg vijeka, Zemaljski muzej Bosne i Hercegovine, Sarajevo.

Szope M.(1985), Miecze ze zbiorów Muzeum Okregowego w Tarnowie, „Tarnoviana”, s. $205-218$.

Żabiński G. (2017), A Late Medieval Sword from the River Wista near Gniew (Mewe) in Pomerelia, „Fasciculi Archaeologiae Historicae”, 30, s. 163-179, https://doi.org/I0.23858/FAH30.2017.014

Żabiński G., Rzeszotarska-Nowakiewicz A., Nowakiewicz T., Kontny B., Kucypera P. (2015), A Possible Roman Period Sword from Grzybowo (Grzybowen), Masuria, NE Poland. The Archaeological and Technological Context, "Gladius”, 36, s. 97-140, https://doi.org/10.3989/gladius.2016.0006

\section{Summary}

The article presents an iron sword discovered in 2013 during archaeological excavations in Wolin (West Pomeranian Voivodeship, Poland). The find survived in a fragment which consists of a broken blade and a hilt with cross-guard and pommel. The blade is deformed by corrosion, with a narrow fuller. On the lower part of this fragment there are signs made by yellow metal (copper alloy ?). The cross-guard is strong and solidly rectangular, the arms are waisted and expand at the ends. The handle is topped with a disc-form of pommel.

The typological analysis of the sword is quite simple. Based on general proportions and metrics, the sword blade can be classified as type XIIIa by E. Oakeshott, popular between the late $13^{\text {th }}$ and early $15^{\text {th }}$ century. The cross-guard belongs to the style 2 in his classification, which has a wide chronological framework, and the pommel corresponds to type $\mathrm{J}$ popular between the half of $\mathrm{I}^{\text {th }}$ and $\mathrm{I}^{\text {st }}$ quarter of $\mathrm{I} 5^{\text {th }}$ century. Based on all these data, the sword from Wolin can be dated probably to $2^{\text {nd }}$ half of $13^{\text {th }}$ and $\mathrm{I} 4^{\text {th }}$ century ( $\mathrm{I}^{\text {st }}$ half ?). 
Sword from Wolin is one of the 36 swords in type XiIIa in Poland, and one of the II on the territory of Western Pomerania.

Keywords: Western Pomerania, Wolin, late medieval, Głosek, Oakeshott, swords

Andrzej Janowski

Polska Akademia Nauk

Instytut Archeologii i Etnologii

e-mail: a.janowski@iaepan.szczecin.pl 